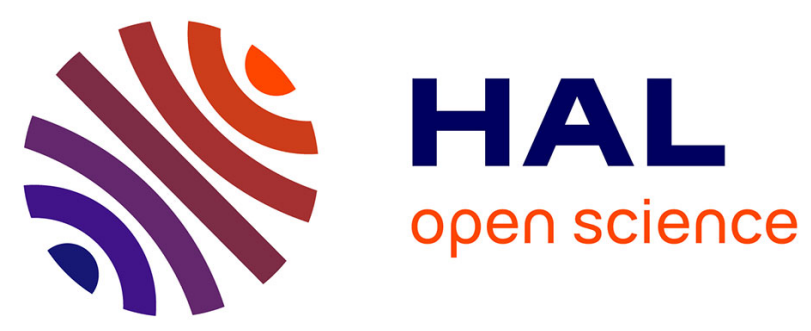

\title{
Study of an AuNPs functionalized electrode using different diazonium salts for the ultra-fast detection of $\mathrm{Hg}(\mathrm{II})$ traces in water
}

Emelyne Gervais, Yara Aceta, Pierre Gros, David Evrard

\section{- To cite this version:}

Emelyne Gervais, Yara Aceta, Pierre Gros, David Evrard. Study of an AuNPs functionalized electrode using different diazonium salts for the ultra-fast detection of $\mathrm{Hg}$ (II) traces in water. Electrochimica Acta, 2018, vol. 261, pp. 346-355. 10.1016/j.electacta.2017.12.136 . hal-01692696

\section{HAL Id: hal-01692696 https://hal.science/hal-01692696}

Submitted on 25 Jan 2018

HAL is a multi-disciplinary open access archive for the deposit and dissemination of scientific research documents, whether they are published or not. The documents may come from teaching and research institutions in France or abroad, or from public or private research centers.
L'archive ouverte pluridisciplinaire HAL, est destinée au dépôt et à la diffusion de documents scientifiques de niveau recherche, publiés ou non, émanant des établissements d'enseignement et de recherche français ou étrangers, des laboratoires publics ou privés. 


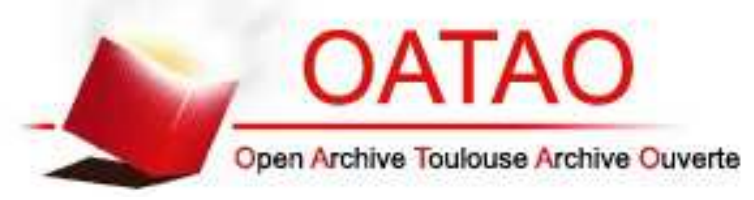

\section{Open Archive TOULOUSE Archive Ouverte (OATAO)}

OATAO is an open access repository that collects the work of Toulouse researchers and makes it freely available over the web where possible.

This is an author-deposited version published in : http://oatao.univ-toulouse.fr/ Eprints ID : 19402

To link to this article : DOI:10.1016/j.electacta.2017.12.136

URL : https://doi.org/10.1016/j.electacta.2017.12.136

\section{To cite this version :}

Gervais, Emelyne and Aceta, Yara and Gros, Pierre and Evrard, David Study of an AuNPs functionalized electrode using different diazonium salts for the ultra-fast detection of $\mathrm{Hg}(\mathrm{II})$ traces in water. (2018) Electrochimica Acta, vol. 261. pp. 346-355. ISSN 0013-4686

Any correspondence concerning this service should be sent to the repository administrator: staff-oatao@ listes-diff.inp-toulouse.fr 


\title{
Study of an AuNPs functionalized electrode using different diazonium salts for the ultra-fast detection of $\mathrm{Hg}$ (II) traces in water
}

\author{
Emelyne Gervais ${ }^{a}$, Yara Aceta ${ }^{b}$, Pierre Gros ${ }^{a}$, David Evrard ${ }^{a}{ }^{*}$ \\ a Laboratoire de Génie Chimique, Université de Toulouse, CNRS, INPT, UPS, Toulouse, France \\ ${ }^{\mathrm{b}}$ Université de Rennes, CNRS, ISCR-UMR 6626, F-35000, Rennes, France
}

Keywords:

Gold nanoparticles

Diazonium salts

Mercury detection

Modified electrode

Interface stability

\begin{abstract}
A B S T R A C T
Chemically-prepared gold nanoparticles (AuNPs) were drop-casted onto bare glassy carbon (GC) and on GC functionalized by two different diazonium salts bearing either nitro $\left(\mathrm{NO}_{2}\right)$ or thiol ( $\left.\mathrm{SH}\right)$ groups. The resulting interfaces were characterized by field emission gun scanning electron microscopy (FEG-SEM) and cyclic voltammetry in $\mathrm{H}_{2} \mathrm{SO}_{4}$. The micrographs evidenced different densities of AuNPs depending on the substrate, bare GC affording denser deposits than diazonium-functionalized GC. The stability of the interfaces was evaluated over one month and showed higher recovery of active surface area (up to $91 \%$ depending on the storage conditions) for AuNPs deposited on diazonium-functionalized GC than on bare GC. The three electrodes were also tested for $\mathrm{Hg}(\mathrm{II})$ trace detection by using Square Wave Anodic Stripping Voltammetry (SWASV) and a preconcentration time shortened from $300 \mathrm{~s}$ to $30 \mathrm{~s}$. In such conditions, a linear response was obtained in the range $1-10$ nmoll $^{-1}$ together with a normalized sensitivity up to 17 times higher than that reported in our previous works dealing with electrodeposited AuNPs.
\end{abstract}

\section{Introduction}

As a member of the heavy metals family, mercury is one of the most problematic pollutants causing major environment contaminations. It is present in the ecosystem because of natural processes such as volcanism, but mostly because of anthropogenic discharges from gold mines or industries. It is then widespreaded in soils $[1,2]$, atmosphere [3,4] and animals [5,6]. In his organometallic form (methylmercury $\mathrm{MeHg}$ ) it bioaccumulates all along the food chain $[7,8]$ and may thus be present in quite high quantities in the human food. When a poisoning occurs, effects on health include lungs, heart, liver, kidney and brain pathologies $[9,10]$. To control the widespreading of this micropollutant, the World Health Organization has delivered a guideline value of $6 \mu \mathrm{gl}^{-1}$ (ca. $30 \mathrm{nmoll}^{-1}$ ) for drinking water [11], but in Europe, the European Water Framework Directive set an even more strict standard of $0.07 \mu \mathrm{gl}^{-1}$ (ca. $0.3 \mathrm{nmol}^{-1}$ ) in addition of classifying mercury and his compounds as priority dangerous substances [12]. Thus, there is a need for detection tools against this pollutant capable of detecting traces

\footnotetext{
* Corresponding author.

E-mail address: evrard@chimie.ups-tlse.fr (D. Evrard).
}

levels.

In analytical laboratories, mercury in surface water is detected with classical spectroscopic techniques such as cold-vapor atomic absorption spectrometry or cold-vapor atomic fluorescence spectrometry with good accuracy, sensitivity and selectivity. However, in addition of the cost of these equipments, the measurements are ex-situ meaning that water samples have to be collected, transported and even stored prior to analysis. Concerning mercury, this is a great cause of contamination during the samples storage and transportation [13,14]. It then appears necessary to develop portable sensors which can provide in-situ measurements and real time analysis. To this purpose, electrochemical sensors can be a good alternative due to their portability, low costs production and maintenance, and good sensitivity. They are also a great choice for traces detection in regards of the possibility of electrode functionalization that affords better selectivity and sensitivity [15]. Electrode modification can be operated with graphene [16], biological materials like DNA [17], carbon nanotubes [18] and so on. In particular, gold nanoparticles (AuNPs) are an interesting sensing material for electrode modification because of their good affinity with mercury and their electrocatalysis features [19-21].

In our group, AuNPs were electrodeposited on a glassy carbon electrode throught different electrochemical techniques and 
showed a great ability to detect mercury traces [22]. Because chloride ions were shown to play an important role in the detection, a desorption step was added to the detection process and a concentration of mercury of $19 \mathrm{pmoll}^{-1}$ was reached for a submarine groundwater discharge sample [23]. In an alternative way, chemically prepared AuNPs were used to functionalize a GC electrode reaching a LOD of 1 pmoll $^{-1}$ [24]. However, the remaining sensor suffered a poor stability over time and electrochemical treatments.

In this present study we used diazonium salts diazonium salts in order to improve the stability of the particle deposits on the carbon surface by acting as a link between AuNPs and glassy carbon. It has been shown many times that the organic layer obtained by reduction of diazonium ions is covalently bonded to the glassy carbon [25,26]. Besides, harsh treatments like power sanding or radical attacks are the only ways to remove this layer as it resists ultrasonic treatments [27]. Then, the most interesting question is to determine the optimal terminal group on the diazoniums that could strongly interact with the AuNPs in order to stabilize them. In the literature, one of the most and commun diazonium used is the 4-mercaptobenzene diazonium, that is call SH in this present paper. Indeed, it is known that the interactions between sulfur and gold are covalent with a binding energy of $154.4 \mathrm{~kJ} \mathrm{~mol}^{-1}$ [28]. This strong bonding was confirmed for AuNPs deposited on a $\mathrm{SH}-$ modified electrode [29-31]. However, like the commonly studied alkanethiols Self-Assembled Monoloyers, the S-Au in this configuration is labile and can be destabilized by oxidation [32]. The use of nitrobenzene diazonium (NBD) for the improvement of the AuNPs stability is not as popular as SH. In most studies, NBD is used in order to reduce its terminal nitro group in an amine before AuNPs deposition [33]. Indeed, the bonding energy of $\mathrm{NH}-\mathrm{Au}$ is $153.6 \mathrm{~kJ} \mathrm{~mol}^{-1}$ [34] whereas the $\mathrm{NO}_{2}-\mathrm{Au}$ was calculated to be $8.37 \mathrm{~kJ} \mathrm{~mol}^{-1}$ [35]. However, this NBD diazonium is known for growing in multilayer structure, especially when the grafting is not controlled (cyclic voltammetry) or when the amount of charge used is important (long time electrolysis). It presents a rough morphology where holes or globuled structures appear [36,37]. Thus, AuNPs may be suspected to interpenetrate into the layer at differents depths [38] allowing the current to run from the analyte solution to the electrodes through the metallic particles. The NBD diazonium may be then supposed to afford a stabilizing effect on the AuNPs mostly because of steric interactions.

In the present work we compared the stability of GC electrodes functionalized with chemically prepared AuNPs with or without the presence of a layer of diazonium (NBD or SH) between the substrate and the particles. The functionalization of the electrodes was followed with respect to two electrochemical probes, ferricyanide and hexaammineruthenium(III), and the resulting interfaces were characterized by field emission gun scanning electron microscope (FEG-SEM) observations and electrochemical processes. The stability of the sensors in different storage conditions was evaluated and discussed. Finally, the analytical performances of the modified electrodes were determinated against the detection of $\mathrm{Hg}(\mathrm{II})$ traces.

\section{Experimental}

\subsection{Reagents and apparatus}

All the solutions were prepared using ultrapure water (Milli-Q Millipore, $18.2 \mathrm{M} \Omega \mathrm{cm}$ ). 99.5\% $\mathrm{NaNO}_{2}$, 4-aminothiophenol $(97 \%$ $\mathrm{NH}_{2} \mathrm{C}_{4} \mathrm{H}_{4} \mathrm{SH}$ ) and 4-nitrobenzene diazonium tetrafluoroborate $\left(97 \% \mathrm{C}_{6} \mathrm{H}_{4} \mathrm{~N}_{3} \mathrm{O}_{2} \mathrm{BF}_{4}\right)$ were purchased from Sigma Aldrich. $\mathrm{HAuCl}_{4} \cdot 3 \mathrm{H}_{2} \mathrm{O}$ pro-analysis grade and $99 \% \mathrm{KNO}_{3}$ were supplied by
Acros Organics. Sodium citrate $\left(\mathrm{C}_{6} \mathrm{H}_{5} \mathrm{Na}_{3} \mathrm{O}_{7}\right)$ and $\mathrm{Ru}\left(\mathrm{NH}_{6}\right) \mathrm{Cl}_{3}$ were purchased from Alfa Aesar. $\mathrm{K}_{3}\left[\mathrm{Fe}(\mathrm{CN})_{6}\right]$ was purchased from Merck. 95\% $\mathrm{H}_{2} \mathrm{SO}_{4}$ Normapure grade was obtained from VWR Prolabo. $\mathrm{Hg}(\mathrm{II})$ solutions were prepared by dilution of [separateuncertainty] $1000 \pm(4) \mathrm{mg} \mathrm{l}^{-1} \mathrm{Hg}\left(\mathrm{NO}_{3}\right)_{2}$ standard solution (TraceCERT grade, Sigma Aldrich) and acidified to $\mathrm{pH} 2$ with concentrated $34-37 \% \mathrm{HCl}$ (Plasmapure grade, SCP Science). All the experiments were performed at room temperature in a three-electrode glass cell using a PGSTAT $128 \mathrm{~N}$ potentiostat (Metrohm Autolab, Utrecht, Netherlands) connected to a computer running with NOVA 1.10 software package. A Radiometer saturated calomel electrode $\mathrm{Hg}$ / $\mathrm{Hg}_{2} \mathrm{Cl}_{2} / \mathrm{KCl}$ (sat) was used as a reference electrode and a Metrohm glassy carbon (GC) wire as the auxiliary electrode. The working electrode was a Radiometer rotating GC disk sealed in Teflon $(3 \mathrm{~mm}$ diameter, $A=7.07 \mathrm{~mm}^{2}$ ) or a pyrolized photoresist film (PPF) plate ( $6 \mathrm{~mm}$ diameter, $\mathrm{A}=28.3 \mathrm{~mm}^{2}$ ) prepared at the Institut des Sciences Chimiques de Rennes according to published procedure $[39,40]$. PPF was used for diazonium layer thickness measurements, as it is known to react like GC while being as flat as HOPG [41]. The electrochemical cell was constantly maintained in a Faraday cage in order to minimize the electrical interferences. The solutions were deaerated with a $\mathrm{N}_{2}$ stream for $10 \mathrm{~min}$ prior to each experiment. A $\mathrm{N}_{2}$ atmosphere was also maintained over the solution during the corresponding experiments.

\subsection{Synthesis of the gold nanoparticles (AuNPs)}

The AuNPs were synthesized by the classical Turkevich method [42]. Prior to any use, all glassware was cleaned with aqua regia (3:1 $\left.\mathrm{HCl} / \mathrm{HNO}_{3}\right)$ and rinsed with ultrapure water. $22 \mathrm{mg}\left(8.5 \times 10^{-5} \mathrm{~mol}\right)$ of sodium citrate was dissolved in $30 \mathrm{ml}$ of Milli-Q water and then heated under reflux. $10 \mathrm{ml}$ of an aqueous $\mathrm{HAuCl}_{4}$ solution $(9.9 \mathrm{mg}$, $2.5 \times 10^{-5} \mathrm{~mol}$ ) was then added followed by $10 \mathrm{ml}$ of ultrapure water. The mixture was heated for $20 \mathrm{~min}$ and left to cool at room temperature for at least $1 \mathrm{~h}$ before storing at $4{ }^{\circ} \mathrm{C}$. The final solution had a concentration of AuNPs of $4.8 \mathrm{nmoll}^{-1}$ calculated with Equation (1).

$C_{\text {AuNPs }}=\frac{N_{\text {AuNPS }}}{V_{S o l} N_{a}}$

where $V_{\text {sol }}$ is the volume solution, $N_{a}$ the Avogadro number and $N_{A u N P s}$ the gold nanoparticles number in the solution calculated with Equation (2).

$N_{A u N P S}=\frac{V_{A u}}{V_{A u N P}}=\frac{m(A u)}{\rho_{A u}} \frac{3 \pi R_{A u N P S}^{3}}{4}$

where $V_{A u}$ is the gold volume in the solution and $V_{A u N P}$ the volume occupied by one gold nanoparticle considering a diameter of $15 \mathrm{~nm}$ (see Section 3.1).

The final colloidal solution was stable for one month.

\subsection{Synthesis of 4-thiophenol diazonium}

To synthesize the 4-thiophenol diazonium (SH), $120 \mu \mathrm{l}$ of a $0.1 \mathrm{moll}^{-1} \quad \mathrm{NaNO}_{2}$ aqueous solution was slowly added to a $0.1 \mathrm{~mol} \mathrm{l}^{-1} \mathrm{HCl}$ solution containing $1 \mathrm{mg}(0.01 \mathrm{mmol})$ of $4-$ aminothiophenol at $4{ }^{\circ} \mathrm{C}$. The solution became yellow immediately and the reaction was left to run for $10 \mathrm{~min}$ before use.

\subsection{Preparation and modification of the electrode}

Before each modification the GC surfaces were sanded with silicon carbide grinding paper (grit 1200) for $5 \mathrm{~s}$ in order to remove 
any residues from previous uses. Then they were successively polished by $9 \mu \mathrm{m}, 3 \mu \mathrm{m}, 1 \mu \mathrm{m}$ and $0.25 \mu \mathrm{m}$ Mecaprex diamond suspensions (Presi) on clothes polishing pads for $1 \mathrm{~min}$ at $400 \mathrm{rpm}$, $300 \mathrm{rpm}, 200 \mathrm{rpm}$ and $100 \mathrm{rpm}$ respectively. Between each polishing step the surfaces were rinsed with ethanol and dried with Kimtech paper. Finally, they were rinsed in an ultrasonic ethanol bath for 5 min twice, and then dried using a $\mathrm{N}_{2}$ stream. The diazonium salts concentration was $1.5 \mathrm{mmoll}^{-1}$ in the electrochemical cell and they were grafted by constant potential electrolysis for $300 \mathrm{~s}$ in $0.1 \mathrm{mmol}^{-1} \mathrm{HCl}$ at $0 \mathrm{~V}$ for the NBD and $-0.3 \mathrm{~V}$ for the SH. After this step the surfaces were rinsed in an ultrasonic ethanol bath for $5 \mathrm{~min}$ in order to remove weakly adsorbed moieties and then dried under a $\mathrm{N}_{2}$ stream. The AuNPs deposit was achieved by drop-casting: a $50 \mu \mathrm{l}$ drop of the colloidal suspension was placed on the GC, GC/NBD or GC/SH surfaces and left to dry overnight at room temperature.

\subsection{Characterization of the AuNPs and the functionalized electrodes}

The size of the synthesized AuNPs was determined by transmission electron microscopy (TEM) using a JEOL JEM 1400 equipment with an accelerating voltage of $120 \mathrm{kV}$; Image software was used to analyze multiple images and the size distribution was calculated with OriginPro 8.5. To get accurate results, 5523 particles were analyzed to obtain both the perimeter and the area for each one and then to extract two diameter values. The final size distribution was calculated using the resulting mean diameter. The AuNPs zeta potential was determined with a Zetasizer Nanoseries ZS90 from Malvern Instruments. The GC/AuNPs and GC/diazonium/ AuNPs surfaces were characterized by field emission gun scanning electron microscope (FEG-SEM) with a JEOL JSM 7800F with accelerating voltage of $15 \mathrm{kV}$ and a homemade MATLAB program was used to determine the particles density and diameter from the images. The calculations were completed on 8 pictures for each interface in order to get the most accurate results. Diazonium film thickness was measured by atomic force microscopy (AFM) at the Institut des Technologies Avancées en sciences du Vivant (ITAV USR 3505, Toulouse) using a JPK NanoWizard II (Life Science Version) running a MSNL-E probe in contact mode.

\subsection{Stability of the deposits against storage conditions}

Each functionalized electrode was left to rest in three different media for one month. The first batch of electrode was left at ambient air in a glass pot filled with Silicagel in order to prevent excess humidity; the second was placed in $0.01 \mathrm{~mol} \mathrm{l}^{-1} \mathrm{HCl}$ at $4{ }^{\circ} \mathrm{C}$; finally the third one was immersed in a $0.05 \mathrm{moll}^{-1}$ phosphate buffer solution $(\mathrm{pH}=7)$ at $4{ }^{\circ} \mathrm{C}$. Every week, an activation process in $0.5 \mathrm{~mol} \mathrm{l}^{-1} \mathrm{H}_{2} \mathrm{SO}_{4}$ followed by a $3 \mathrm{nmol}^{-1}$ mercury detection were conducted. The evolution of the interfaces was followed with calculation of the average particle densities before and after the experiments obtained by FEG-SEM imagery.

\subsection{Detection of $\mathrm{Hg}(\mathrm{II})$}

To avoid any type of contamination, every glass material in contact with mercury (electrochemical cell, $\mathrm{Hg}$ (II) solution storage vials, graduated flasks) was heated at $540^{\circ} \mathrm{C}$ for $2 \mathrm{~h}$ and left to chill in the oven for several hours before use. All the $\mathrm{Hg}(\mathrm{II})$ solutions were prepared in a laminar flow hood and stored in two polyethylene zipped bags in a dedicated place. The detection procedure was achieved using Square Wave Anodic Stripping Voltammetry (SWASV) between $0 \mathrm{~V}$ and $0.8 \mathrm{~V}$ with the following parameters: cleaning potential $=0.8 \mathrm{~V}$, cleaning time $=15 \mathrm{~s}$, preconcentration potential $=0 \mathrm{~V}$, preconcentration time $=30 \mathrm{~s}$, pulse amplitude $=25 \mathrm{mV}$, step amplitude $=5 \mathrm{mV}$, frequency $=200 \mathrm{~Hz}$. During the preconcentration time the solution was stirred by rotating the working electrode at $2000 \mathrm{rpm}$. A blank signal was also recorded after each scan by setting a preconcentration time 10 times smaller than the main one; the signals were then subtracted in order to free the final signal from the background vagaries. Each experience was repeated three times in order to evaluate the standard deviation for each measurement.

\section{Results and discussion}

\subsection{Characterization of the AuNPs}

Fig. 1a shows the TEM image of the AuNPs synthesized with the Turkevich method. Most of the particles exhibited an elliptic shape but some triangular shapes were also observed (not shown). From the size distribution a mean diameter for the whole colloidal solution of $15 \mathrm{~nm}$ was determined (Fig. 1b). These results are characteristic of this synthesis [43-45]. The particles were further characterized by evaluating their zeta potential and an average value of $-45 \mathrm{mV}$ was obtained which is consistent with a good stability of the suspension. Indeed, the AuNPs solution was stable for one month before some visible aggregation signs appeared: the color slowly turned from red to purple and black aggregates formed in the solution. At this point the solution was not used anymore and a new AuNPs synthesis was conducted.

\subsection{Functionalization of the electrode}

The functionalization of the GC electrode with 4-nitrobenzene diazonium (NBD) and 4-thiophenol diazonium (SH) was first conducted by cyclic voltammetry in order to characterize the grafting process of the two salts on the carbon surface. The corresponding voltammograms are given on Fig. A.8. On the first scan the typical reduction peak corresponding to the diazonium grafting was observed at 0.05 and $-0.15 \mathrm{~V}$ for NBD and SH, respectively. These potential values were in good agreement with the greater electron withdrawing effect of the nitro group compared to that of the thiol one. On the second scan these peaks disappeared because of the well-known self-inhibition phenomenon of such films [27]. However, grafting by using multiple cyclic scans is known to induce thick, disordered multilayer structures that exhibit defects [36,46]. As a consequence, constant potential electrolysis (CPE) was rather used in order to reach better control and reproducibility on the resulting structuration of the grafted layer. Typically, the grafting process was achieved by performing CPE during $300 \mathrm{~s}$ at $0 \mathrm{~V}$ and $-0.3 \mathrm{~V}$ for NBD and SH, respectively. These conditions were chosen in order to produce multilayered, self-inhibiting films.

The last step of the electrodes functionalization was then conducted by depositing AuNPs on GC and GC/diazonium interfaces.

\subsection{Characterization of the functionalized electrode}

The successive steps of the electrode functionalization process were checked by studying the electrode response to two different electrochemical probes, namely ferricyanide $\mathrm{Fe}(\mathrm{CN})_{6}^{3-}$ and hexaammineruthenium(III) $\mathrm{Ru}\left(\mathrm{NH}_{3}\right)_{6}^{3+}$. On bare GC, a quasi-reversible system with a $\Delta \mathrm{Ep}=147 \mathrm{mV}$ was observed for $\mathrm{Fe}(\mathrm{CN})_{6}^{3-}$ (Fig. 2a-c, solid lines), in accordance with many previous reports [47-49]. On GC/AuNPs electrode (Fig. 2a, dotted line), both anodic and cathodic peak currents significantly enhanced and the $\Delta \mathrm{Ep}$ slightly decreased (ca. $91 \mathrm{mV}$ ). These observations were consistent with the 

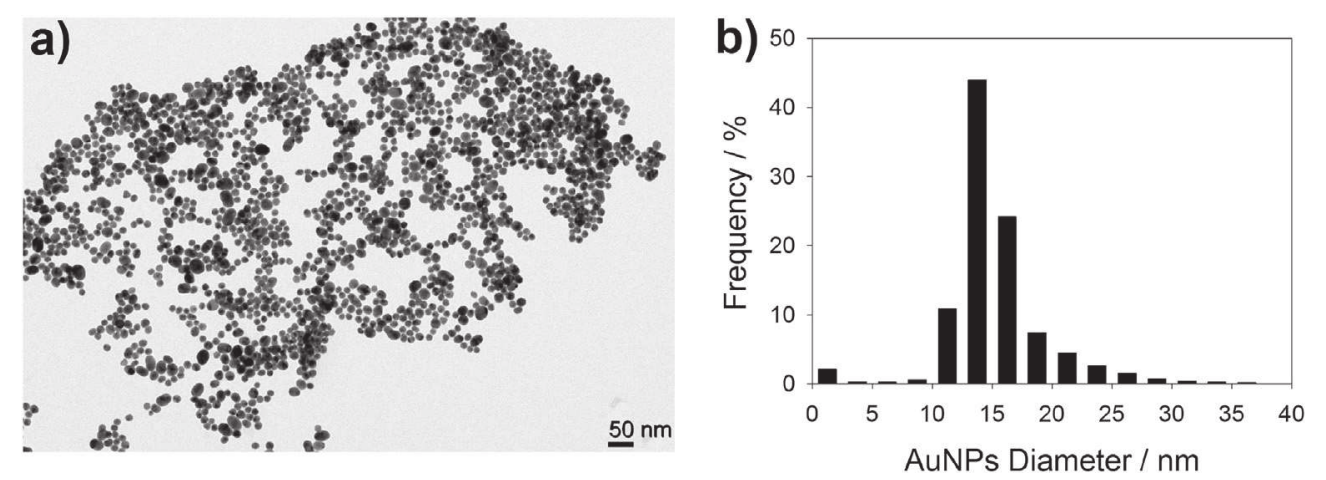

Fig. 1. (a) TEM images of AuNPs synthesized with the Turkevich method and (b) the corresponding size distribution. See Section 2.5 for experimental details.

\section{GC/AuNPs}
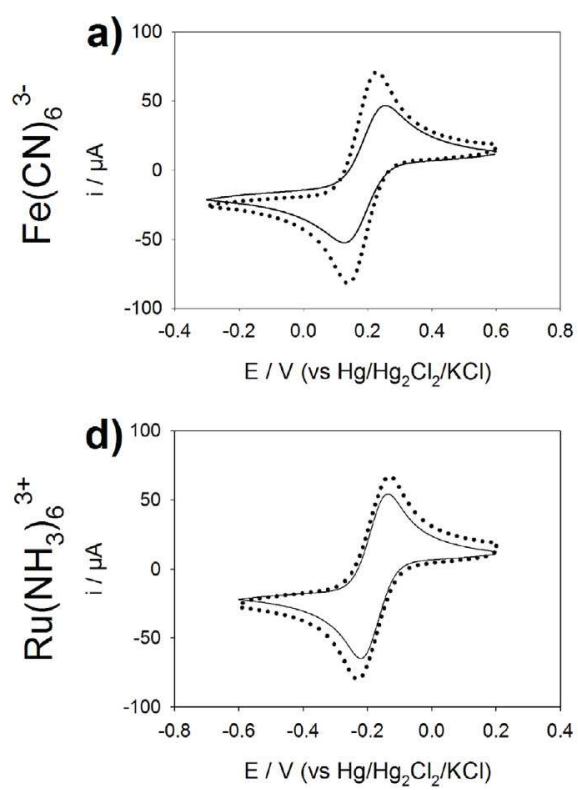

GC/NBD/AuNPs
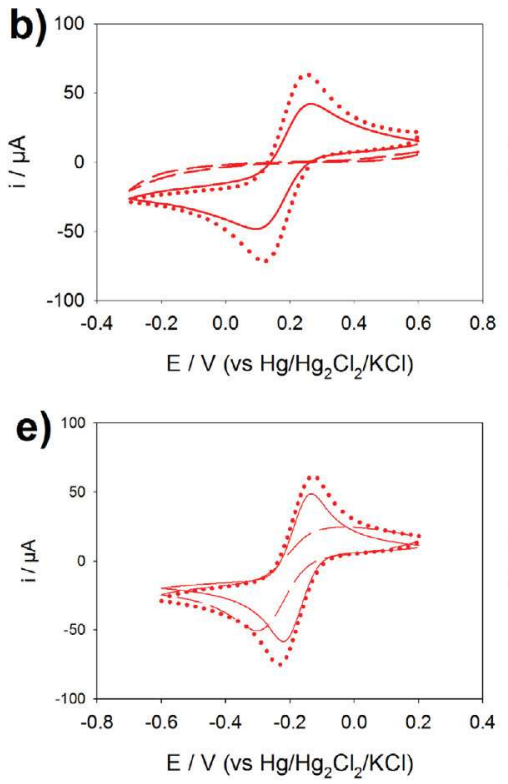

GC/SH/AuNPs
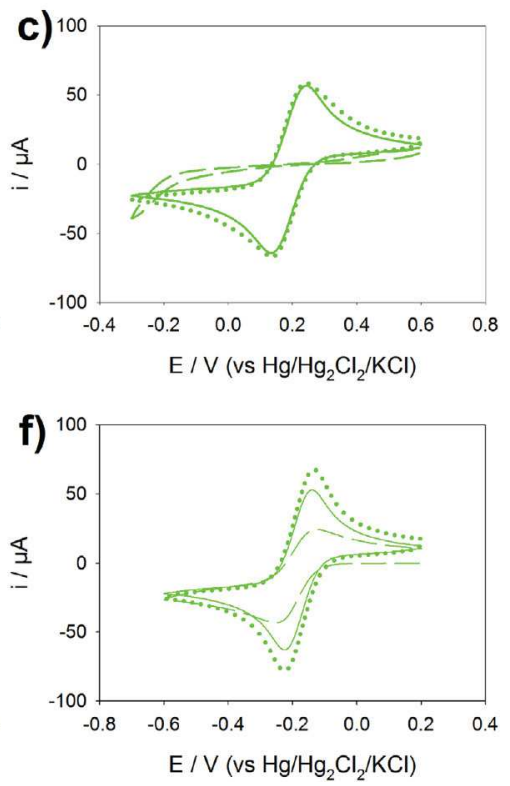

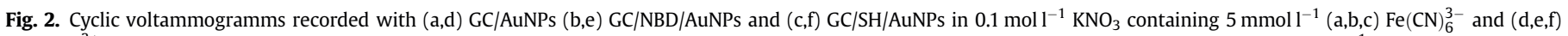
$\mathrm{Ru}\left(\mathrm{NH}_{3}\right)_{6}^{3+}$. Solid line: bare GC; dashed line: GC/diazonium; dotted line: GC/diazonium/AuNPs (except a and d: GC/AuNPs). Potential scan rate: $100 \mathrm{mVs}{ }^{-1}$.

increase in active surface area due to the presence of the AuNPs and with their electrocatalytic effect, respectively. When NBD was grafted onto GC, the signal for $\mathrm{Fe}(\mathrm{CN})_{6}^{3-}$ was totally suppressed (Fig. 2b, dashed line). Keeping in mind that this latter probe redox reactivity proceeds via an inner-sphere mechanism, this observation suggested that NBD grafting afforded a thick layer with no defects that could lead to "pinhole effect" [50]. On the contrary, when AuNPs were drop-casted onto GC/NBD (Fig. 2b, dotted line), the quasireversible signal of $\mathrm{Fe}(\mathrm{CN})_{6}^{3-}$ was restored and enhanced in a similar way compared to what was observed on GC/AuNPs. This is indicative of the presence of AuNPs at the interface between the organic film and the solution, and suggests the electron transfer to proceed via tunneling. These results compared favorably with those previously reported by the group of Hapiot with GC functionalized by polyphenyl acetate multilayers and silver NPs by using ferrocenemethanol as the redox probe [38]. GC/SH electrode exhibited the same behavior as GC/NBD, with the redox signal corresponding to $\mathrm{Fe}(\mathrm{CN})_{6}^{3-}$ which was totally suppressed (Fig. 2c, dashed line). However, GC/SH/AuNPs electrode did not lead to any enhancement of $\mathrm{Fe}(\mathrm{CN})_{6}^{3-}$ redox peak currents nor to any electrocatalytic effect (Fig. 2c, dotted line), suggesting that in this latter case AuNPs behave in a different way to what was observed for GC/AuNPs and $\mathrm{GC} / \mathrm{NBD} /$ AuNPs. This may be indicative of a stronger interaction of the NPs with the p lone-pairs of the sulfur atom than with the $\mathrm{NO}_{2}$ group as expected from the HSAB theory, that may hamper the accessibility of the Au surface. To some extend, one could imagine that the AuNPs penetrate into the organic layer, but complementary studies are required to sustain such a hypothesis. With respect to $\mathrm{Ru}\left(\mathrm{NH}_{3}\right)_{6}^{3+}$, a reversible redox system was recorded both on bare GC and on GC/AuNPs (Fig. 2d). Compared to $\mathrm{Fe}(\mathrm{CN})_{6}^{3-}$, the peak current enhancement was smaller and no decrease in $\triangle \mathrm{Ep}$ was noticed. On GC/NBD, the redox activity of $\mathrm{Ru}\left(\mathrm{NH}_{3}\right)_{6}^{3+}$ was significantly decreased but not totally suppressed, in accordance with the outer-sphere mechanism exhibited by this latter probe (Fig. 2e, dashed line). The reduction peak recorded on the forward scan was smaller and wider and occurred at a more cathodic potential value than on bare GC. On the backward scan, the reoxidation peak was also smaller and ill-defined. As for $\mathrm{Fe}(\mathrm{CN})_{6}^{3-}$, the drop-casting of 
AuNPs onto the GC/NBD resulted in the reappearance of the rapid, reversible redox system of $\mathrm{Ru}\left(\mathrm{NH}_{3}\right)_{6}^{3+}$ (Fig. 2e, dotted line). As for GC/AuNPs, the enhancement of the peak current was smaller than that observed for $\mathrm{Fe}(\mathrm{CN})_{6}^{3-}$ in the same conditions. Finally, on $\mathrm{GC} /$ $\mathrm{SH}$ and GC/SH/AuNPs, the same behavior as on the corresponding NBD electrodes was recorded, confirming that $\mathrm{Ru}\left(\mathrm{NH}_{3}\right)_{6}^{3+}$ is less sensitive to surface functionalization than $\mathrm{Fe}(\mathrm{CN})_{6}^{3-}$.

To better characterize the interfaces functionalized by diazonium, the thickness of the organic film was evaluated by AFM using the contact mode. An average value of $4 \mathrm{~nm}$ was found, in accordance with literature data for the formation of a multilayer film [41].

To fully characterize the interfaces after addition of the AuNPs, SEM imagery was used to observe the morphology of the deposits with and without the diazonium moeity (Fig. 3). As presented in a previous study [24], star and pyramidal geometric arrangements were observed (Fig. 3a). These structures were attributed to $\mathrm{NaCl}$ crystals. Indeed, sodium chloride was one of the by-products of the Turkevich AuNPs synthesis, meaning that during the drying step of the colloid drop on the electrode, $\mathrm{NaCl}$ crystals formed during evaporation. EDX measurements confirmed this statement (see Fig. A.9 Supporting Information). Some black holes and cracks were also observed (Fig. 3c) that were attributed to the formation of a $\mathrm{NaCl}$ skin during the evaporation step. Indeed, as the Teflon in which the GC electrodes were sealed is a hydrophobic material, the colloidal suspension drop-casted on it set with a high contact angle leading to complex drying mechanisms during the evaporation stage. The solvent then evaporated from the top of the drop so that $\mathrm{NaCl}$ concentration locally increased to form a skin. This structure is fragile and is known for creating cracks on the fully dried deposits $[51,52]$. These defects and objects were observed on the three interfaces and disturbed the SEM observation, resulting in the bluriness of the images. For the three interfaces AuNPs settled both on GC or GC/diazonium surface and on the $\mathrm{NaCl}$ crystals (Fig. 3b) as confirmed by EDX (Fig. A.9 of the Supporting Information). The number, location and shape of the $\mathrm{NaCl}$ crystals as well as the ratio of AuNPs that deposited on it are not controlled, thus affecting the deposit reproducibility. This feature needs to be taken into account for the analysis of the results, especially for the electrochemical measurements exploitation. However, AuNPs that did not stand on the crystals arranged as a homogeneous film on the GC or GC/ diazonium surface (Fig. 3d-f). Average diameter and surface densities calculations were performed. The corresponding results are summarized in Table 1. First, and as expected, it was noticeable that the presence or not of an organic layer on the electrode did not changed the average diameter of the AuNPs, meaning the diazoniums did not have any major influence on this physical property. A value around $18 \mathrm{~nm}$ for the three interfaces was determined with SEM pictures analysis (see Table 1), which was slightly bigger than the $15 \mathrm{~nm}$ obtained with the TEM analysis. As long as this results were in the same order of magnitude, this difference was attributed to the blurriness of the SEM pictures that was a source of error during the images processing. Concerning the average AuNPs densities, less particles were deposited on the electrodes modified with the organics layers. Considering the negative charge surface of the AuNPs and the important electron density of the organics layers, this behavior can be the consequence of electrostatic repulsions. However, more studies need to be conducted to confirm this hypothesis. The lower amount of particles on GC/NBD/AuNPs compared to GC/SH/AuNPs may be explained in a first approach with the HSAB theory [53]. Therefore, Au is more likely to interact with $\mathrm{S}$ rather than with $\mathrm{N}$.

\subsection{Activation}

For our study, GC/AuNPs, GC/NBD/AuNPs and GC/SH/AuNPs electrodes were activated with 10 successive scans in sulfuric acid (Fig. $4 a-c)$. For the three interfaces both typical gold oxidation and gold oxides reduction peaks were present at around 1.3 and $0.9 \mathrm{~V}$ respectively [54]. The reduction peak, which is directly related to the gold active surface area for each electrode, had a higher peak current value and a wider shape on GC/AuNPs and GC/SH/AuNPs

Table 1

Characterization of the AuNPs drop-casted on GC or GC/diazonium electrode.

\begin{tabular}{lll}
\hline Interface & Average diameter $(\mathrm{nm})$ & Average density $\left(\right.$ particles $\left.\mu \mathrm{m}^{-2}\right)$ \\
\hline GC/AuNPs & $19 \pm 1$ & $420 \pm 27$ \\
GC/NBD/AuNPs & $18 \pm 1$ & $235 \pm 20$ \\
GC/SH/AuNPs & $18 \pm 1$ & $361 \pm 21$ \\
\hline
\end{tabular}
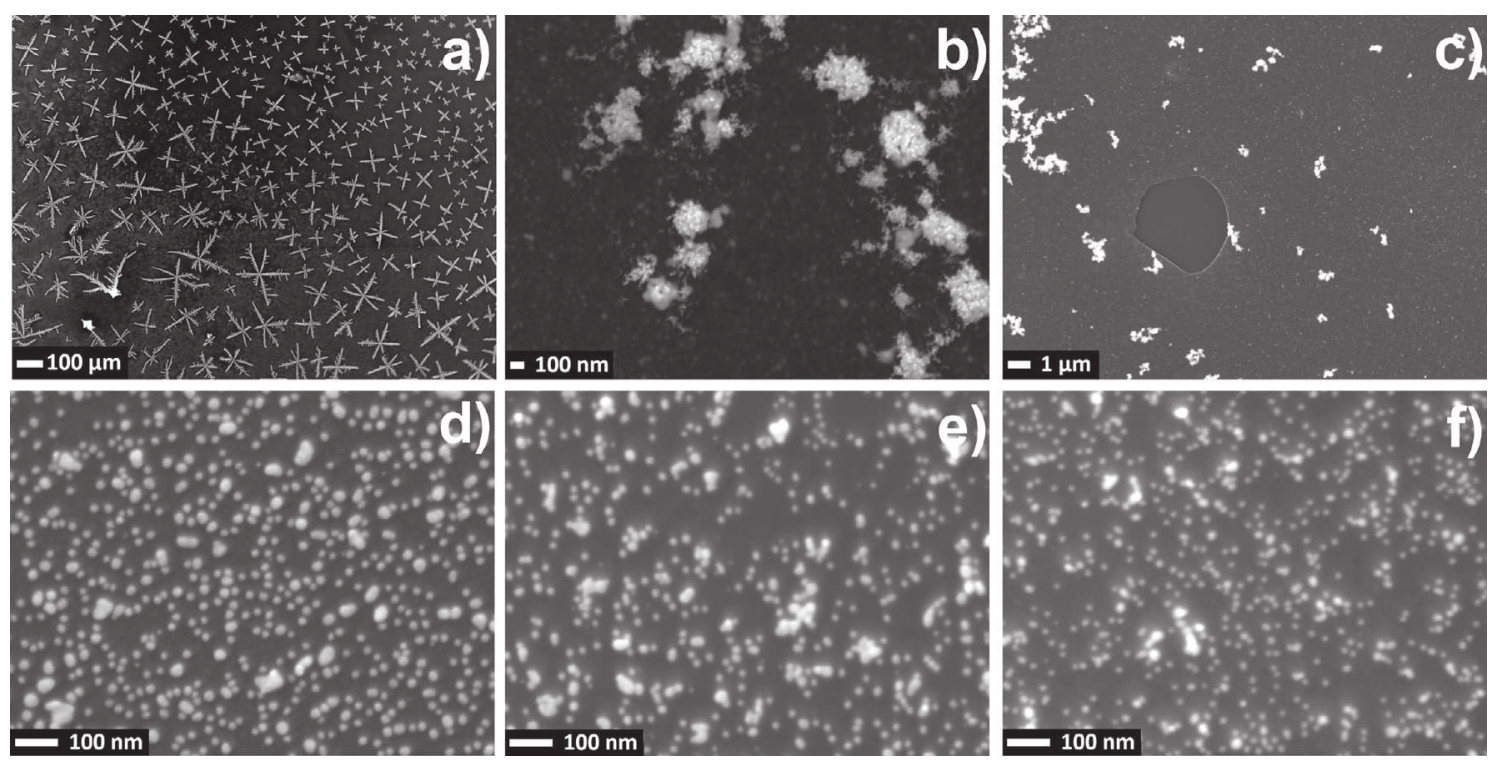

Fig. 3. FEG-SEM images of (a,b,d) GC/AuNPs (e) GC/NBD/AuNPs and (c,f) GC/SH/AuNPs at different magnifications. 

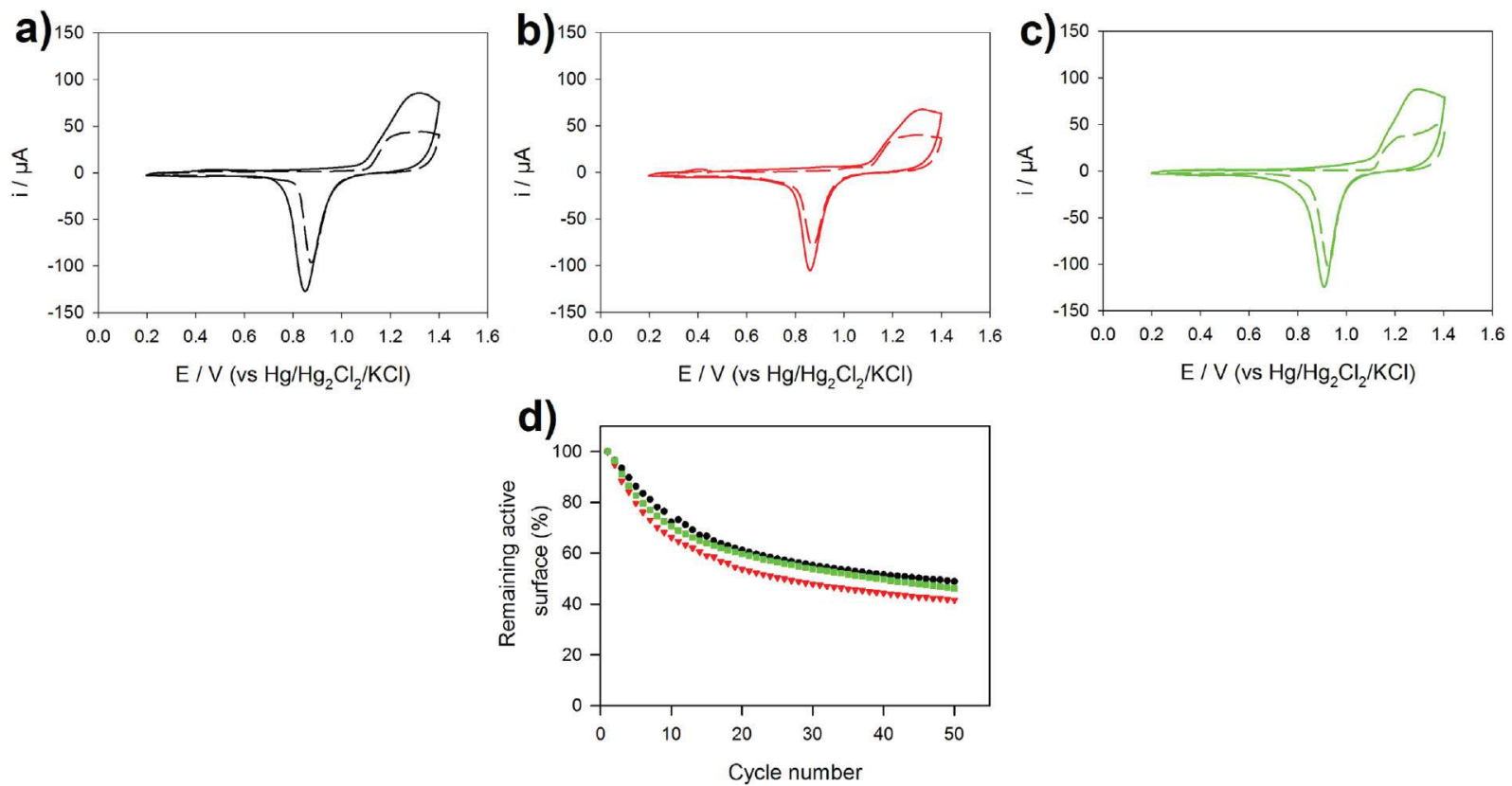

Fig. 4. Cyclic voltammogramms $\left(v=100 \mathrm{mV} \mathrm{s}^{-1}\right.$ ) in $0.5 \mathrm{moll}^{-1} \mathrm{H}_{2} \mathrm{SO}_{4}$ of (a) GC/AuNPs (b) GC/NBD/AuNPs and (c) GC/SH/AuNPs electrodes; 1 st scan in solid line, 10 th scan in dashed line. (d) Evolution of the remaining active surface calculated from the integration of the gold oxides reduction peak for GC/AuNPs (black dots), GC/NBD/AuNPs (red triangles) and $\mathrm{GC} / \mathrm{SH} /$ AuNPs (green squares) during 50 runs of cyclic voltammetry $\left(\mathrm{v}=100 \mathrm{mV} \mathrm{s}^{-1}\right)$ in $0.5 \mathrm{~mol}^{-1} \mathrm{H}_{2} \mathrm{SO}_{4}$. (For interpretation of the references to color in this figure legend, the reader is referred to the Web version of this article.)

meaning the active surface area was more important on these interfaces. This result is consistent with the gold surface densities previously estimated with the SEM pictures analysis. On the other hand, this peak decreased all along the scanning for each electrode, showing a decrease of the AuNPs active surface. This trend was already observed in several studies including one of our previous work with drop-casted AuNPs [24,55,56]. It is the consequence of a dissolution-redeposition mechanism of the AuNPs during the cycling in $\mathrm{H}_{2} \mathrm{SO}_{4}$ : during the oxidation scan the smallest AuNPs dissolve in the solution and redeposited on the remaining AuNPs during the reduction scan, leading to NPs growth and to a subsequent decrease in active surface area.

The three interfaces showed a slight positive shift of the oxides reduction peak after 10 cycles from 0.85 to $0.9 \mathrm{~V}$, this latter corresponding to the reduction peak potential for a bare gold electrode. This behavior showed that the AuNPs not only became bigger because of the dissolution-redeposition mechanism, but their reactivity tended to change until acting like a bare gold electrode, meaning that the crystallographic faces configuration on the surface was changing. In brief, the activation effectively homogenized the particles surface but was also the cause of a significant loss of active surface. To quantify this phenomenon, 50 cyclic voltammograms were recorded in acid media for each functionalization. For the sake of comparaison, the values of the active surface area were obtained by integration of the gold oxides reduction peak for each electrode and normalized with respect to the active surface area value obtained for the first scan. The remaining surface was then plotted against the number of scans (Fig. 4d). During the first 10 runs, the remaining active surface decreased quite fast to reach a value around $70 \%$ meaning that almost one third of the active surface is lost. During the following scans the remaining surface continued to decline but never reached a constant value. At the end of the 50 scans, around only $50 \%$ of the initial gold surface was still detected on the electrodes, some losing even $80 \%$ of the initial gold surface (not shown). This result confirmed that cyclic voltammetry in acidic media is not the most appropriate way to activate the resulting AuNPs because of the important surface loss that will affect the sensitivity of the sensor towards mercury traces detection. However, this procedure was still done on every interface before any other electrochemical measurement because it proved to be efficient for the homogenization of the crystals faces of the AuNPs. It is interesting to point out that this behavior was not observed in our past studies with electrodeposited [22,23] and filtered drop-casted AuNPs [24], possibly because of a different structure configuration and reactivity of the AuNPs.

\subsection{Stability of the deposits}

To evaluate the stability of our systems another strategy was established: Fig. 5 shows the first and $50^{\text {th }}$ cyclic voltamogramms recorded on the three interfaces in aqueous solutions containing $5 \mathrm{mmoll}^{-1} \mathrm{Fe}(\mathrm{CN})_{6}^{3-}$ and $\mathrm{Ru}\left(\mathrm{NH}_{3}\right)_{6}^{3+}$. For both probes the signals showed almost no variation against the peaks potentials and currents meaning that the AuNPs were stable in these conditions.

In order to have more information about the stability of the interfaces against storage conditions, an other stability test was conducted where the electrodes were stored in three different media (see Section 2.6 for experimental details). Briefly, every week during one month, an activation process followed by a $3 \mathrm{nmoll}^{-1}$ mercury detection were conducted on the electrodes placed in different storage conditions. FEG-SEM imagery was used before and after the experiments to quantify the average particle densities. Therefore Table 2 summerizes the percentages of the remaining AuNPs on each electrode after one month of immersion. As expected, leaving the interfaces in ambient air for a long time was not without any consequences on the deposits: only around $30 \%$ of the AuNPs stayed on the interfaces with no noticeable difference between the electrodes with or without an organic layer. One can suggest that this result may be due to the oxidation of the deposits in the air that organic layer could not prevent. Also, considering that a SWASV is conducted every week during this stabitity 
GC/AuNPs
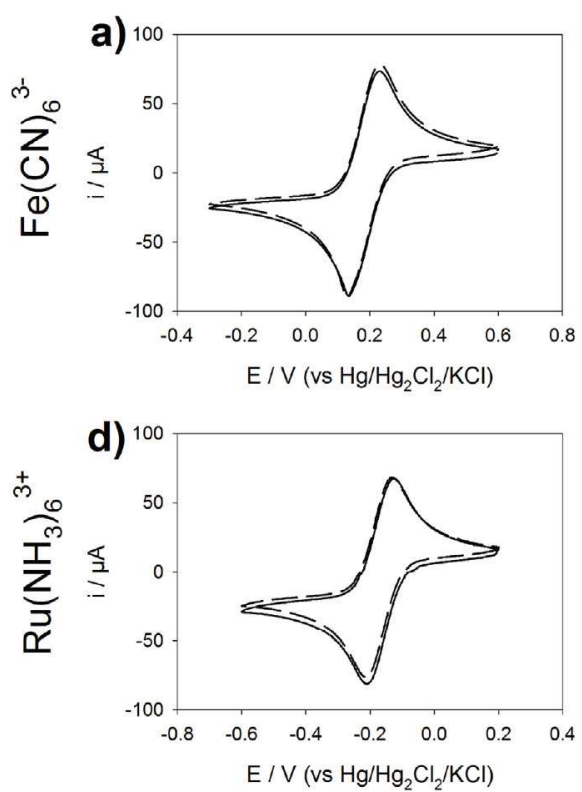

GC/NBD/AuNPs
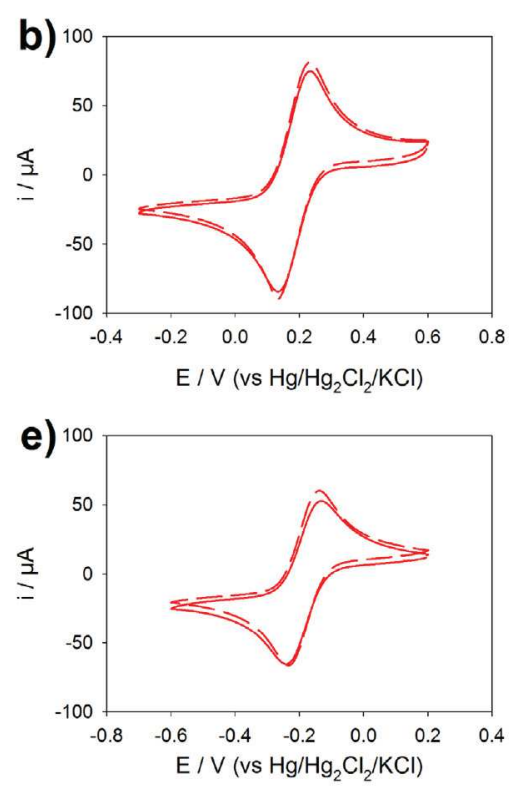

GC/SH/AuNPs
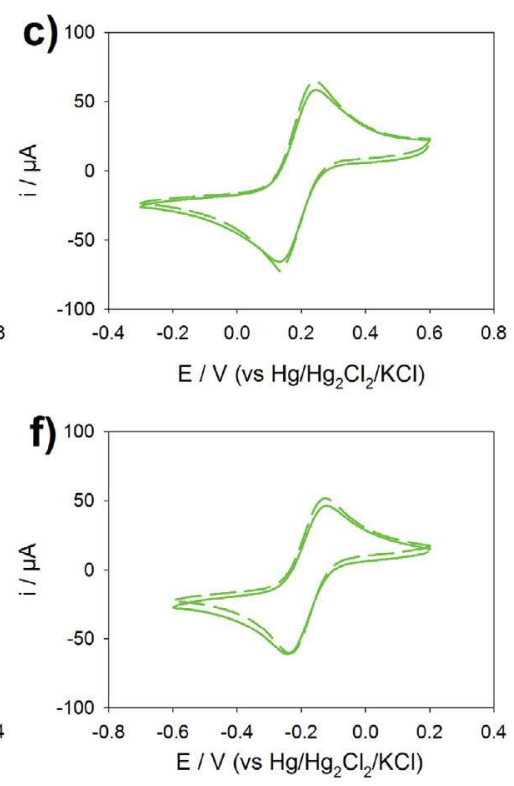

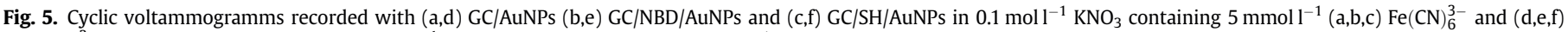
$\mathrm{Ru}\left(\mathrm{NH}_{3}\right)_{6}^{3+}$. Solid line: 1 st scan; dashed line: $50^{\text {th }}$ scan. Potential scan rate: $100 \mathrm{mV} \mathrm{s}^{-1}$.

Table 2

Percentage of the remaining AuNPs for the three functionalized electrodes in the three different media after one month of immersion. Calculations done with the average particle densities values obtained with FEG-SEM imagery; 100\% corresponds to the value before the experiments.

\begin{tabular}{llll}
\hline Interface & Air & Acid & Phosphate buffer \\
\hline GC/AuNPs & $32 \%$ & $16 \%$ & $40 \%$ \\
GC/NBD/AuNPs & $/$ & $91 \%$ & $59 \%$ \\
GC/SH/AuNPs & $26 \%$ & $80 \%$ & $72 \%$ \\
\hline
\end{tabular}

protocol, the deposits are in contact with aqueous solutions frequently. It is known that the deposits contain a non negligible part of crystallized and skin-like salt, so it can be proposed that the deposits could crack during the drying time between each SWASV, leading the deposit to fall into the solution. On the other hand, interesting features are observed in acid and buffered solutions. The organic layers seem to have a stabilizing effect on the AuNPs considering that the electrodes without the diazonium layer show a larger amount of lost AuNPs. This result is even more dramatic in the acid media were the GC/AuNPs interface lost around $85 \%$ of its AuNPs when GC/NBD/AuNPs and GC/SH/AuNPs show only a slight decrease in the number of particles left. Considering the fact that this test involved several activation phases where a loss of active surface area is known to occur, it is quite contradictory to observe that the number of remaining AuNPs can be that stable on some interfaces.

\subsection{Detection of mercury}

$\mathrm{Hg}$ (II) detection was achieved on GC/AuNPs, GC/NBD/AuNPs and GC/SH/AuNPs interfaces by recording SWASV in $0.01 \mathrm{moll}^{-1} \mathrm{HCl}$ following a previously reported procedure $[22,24]$ which used a typical preconcentration time of $300 \mathrm{~s}$. In such conditions and whatever the considered interface, an unexpected behavior of the sensor towards $\mathrm{Hg}(\mathrm{II})$ detection was noticed, illustrating the peculiar reactivity of the drop-casted AuNPs. First, the functionalized electrode failed at recording a proper blank, i.e. a SWASV runned in a $\mathrm{Hg}(\mathrm{II})$-free $0.01 \mathrm{~mol}^{-1} \mathrm{HCl}$ solution showed a peak around $0.65 \mathrm{~V}$ which was characteristic of $\mathrm{Hg}(0)$ reoxidation (Fig. 6, dashed line). This latter peak was systematically observed despite the caution employed for the manipulation of the glassware and solutions in contact with mercury, on every blank performed. Such a result has never been obtained in our previous works dealing with electrodeposited or chemically-prepared AuNPs. Second, upon successive addition of $\mathrm{Hg}$ (II) and subsequent SWASV recording, the expected increase in $\mathrm{Hg}(0)$ reoxidation peak current was recorded together with the appearance of a pre-peak shoulder located around $0.5 \mathrm{~V}$ (Fig. 6, solid line). All along the increase in $\mathrm{Hg}(\mathrm{II})$ amount, this latter pre-peak became larger and better separated from the initial $\mathrm{Hg}(0)$ reoxidation peak. This

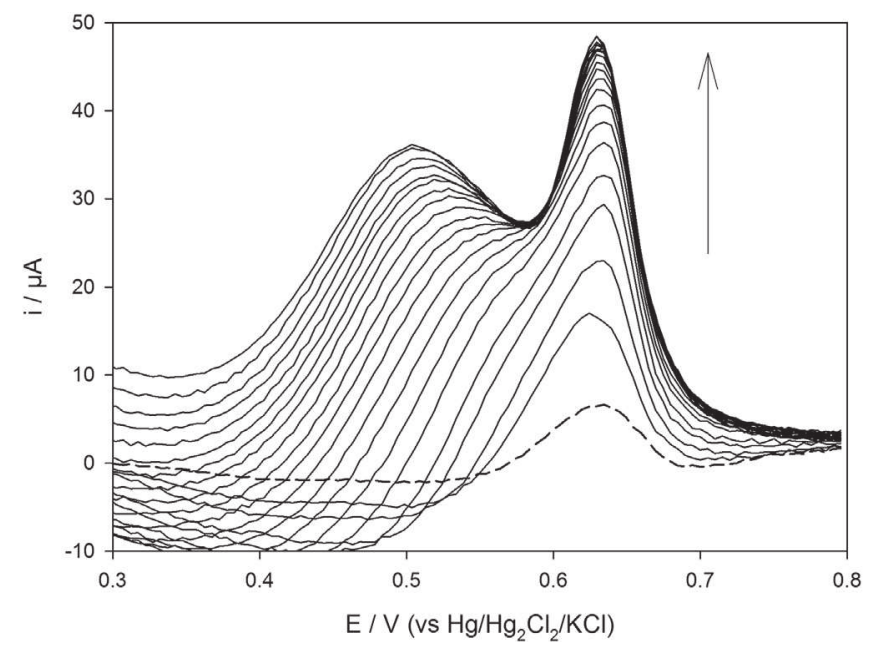

Fig. 6. SWASV obtained in $0.01 \mathrm{~mol}^{-1} \mathrm{HCl}$ for GC/AuNPs for a preconcentration time of $300 \mathrm{~s}$ from 0 to $20 \mathrm{nmoll}^{-1} \mathrm{Hg}$ (II) (step of $1 \mathrm{nmol}^{-1}$ between each SWASV). The dashed line corresponds to the SWASV for $0 \mathrm{nmol}^{-1} \mathrm{Hg}$ (II). 
phenomenon has never been observed before in our group but has been reported once [57], although not commented. However, two hypotheses may be invoked to explain this trend based on the fundamental investigations of Schopf and al $[58,59]$ and Mertens and al [60]: these works stated that reduced mercury settle in the AuNPs as a core-shell structure. If during the stripping stage of the SWASV reduced $\mathrm{Hg}$ does not totally redissolve, the AuNPs may present simultaneously $\mathrm{Au}$ and $\mathrm{Hg}$ surfaces, thus leading to the observation of two peaks at two differents potentials on the resulting voltammogramms. In the meantime, it is proposed that the $\mathrm{Hg}(\mathrm{II})$ reduction leading to the core-shell structure is a fast process followed by a slow diffusion of $\mathrm{Hg}$ inside the AuNPs. As the preconcentration time is important $(300 \mathrm{~s})$ the whole calibration process for all the $\mathrm{Hg}(\mathrm{II})$ concentrations took more than $3 \mathrm{~h}$ to be completed, leaving time enough for the partial core-shell mercury structure to diffuse into the AuNPs. Once again, this phenomenon induces particles structure changes that lead to two different peaks on the resulting voltammogramms. Finally, a third explanation that combines the last two hypotheses may be considered. More specific studies should be conducted to clarify this point.

In order to get rid of this disruptive peak the preconcentration time was decreased so that lower amounts of mercury were reduced on the AuNPs and thus could entirely redissolve in the solution during the stripping step. As the core-shell structure was established after $10 \mathrm{~min}$ but was already important after $2 \mathrm{~min}$, a preconcentration time of $30 \mathrm{~s}$ was fixed. As a validation of our hypothesis, no shoulder was observed on the resulting SWASV, even after several measurements were performed and higher concentrations of analyte were used. However, the blanks still exhibited a peak at $0.65 \mathrm{~V}$. Once again, this behavior was assigned to a higher reactivity of the drop-casted AuNPs compared to that of the electrodeposited and filtered drop-casted ones. The calibration plots obtained for the three electrodes, namely GC/AuNPs, GC/NBD/ AuNPs and GC/SH/AuNPs, are depicted in Fig. 7. Because correct blanks signals could not be obtained, it was not possible to estimate the limit of detection of the sensor, but normalized sensitivities were established for each interface. However, as the drop-casting deposit was not controlled and not reproducible from an electrode to another the sensitivities were also normalized with the active surface of each deposit. This active surface was evaluated with the 10th scan of the activation voltamogramm recorded on

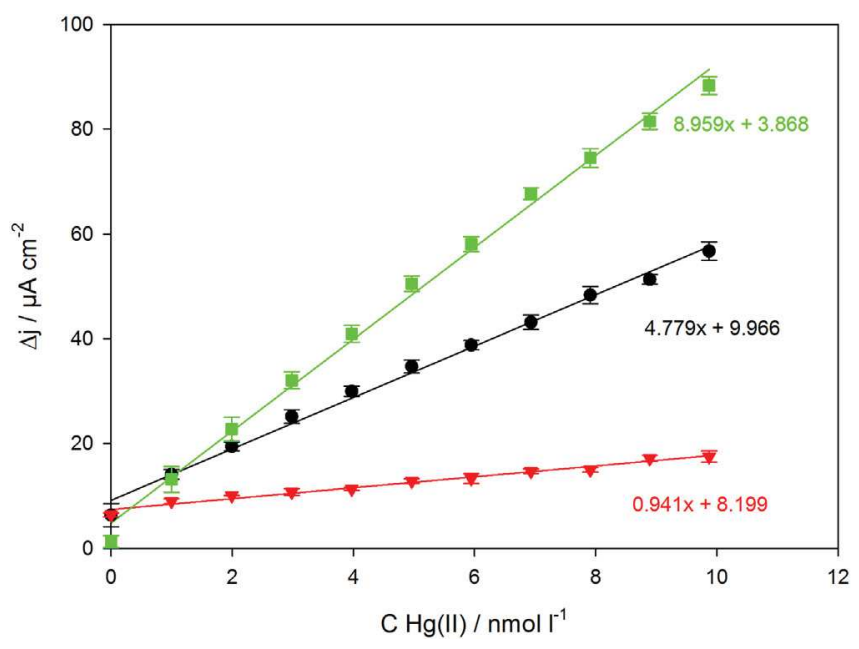

Fig. 7. Calibration plots obtained by SWASV in $0.01 \mathrm{moll}^{-1} \mathrm{HCl}$ for $\mathrm{GC} /$ AuNPs (black circles), GC/NBD/AuNPs (red triangles) and GC/SH/AuNPs (green squares) for a preconcentration time of $30 \mathrm{~s}$. (For interpretation of the references to color in this figure legend, the reader is referred to the Web version of this article.)
Table 3

Normalized sensitivities ( $\mu \mathrm{Alnmol}{ }^{-1} \mathrm{~min}^{-1}$ ) for $\mathrm{GC} / \mathrm{AuNPs}$ and $\mathrm{GC} /$ diazonium electrodes from this study and previous works in a range between 1 and $10 \mathrm{moll}^{-1}$ of $\mathrm{Hg}(\mathrm{II})$. The numbers in brackets correspond to the surface normalized sensitivities calculated with the active surface for each electrode $\left(\mu \mathrm{A} \mathrm{l} \mathrm{nmol}{ }^{-1} \mathrm{~min}^{-1} \mathrm{~cm}^{-2}\right)$. The active surface is obtained by integration of the gold oxides reduction peak on the 10 th scan of the activation voltammogramms.

\begin{tabular}{llllll}
\hline & \multicolumn{2}{l}{$\begin{array}{l}\text { Electro- } \\
\text { deposition }\end{array}$} & & $\begin{array}{l}\text { Drop } \\
\text { casting }\end{array}$ & \\
\cline { 2 - 3 } \cline { 5 - 6 } & {$[22]$} & {$[23]$} & & $\begin{array}{l}\text { Without } \\
\text { diazonium [24] }\end{array}$ & This work \\
\hline GC/AuNPs & 0.23 & 0.60 & & 0.49 & $2.72(9.56)$ \\
GC/NBD/AuNPs & 1 & $/$ & & $0.37(1.88)$ \\
GC/SH/AuNPs & 1 & 1 & & $3.94(17.93)$ \\
\hline
\end{tabular}

each electrode before the mercury detection. In Table 3 the surface normalized sensitivities for the three electrodes from this study were compared, as well as the regular normalized sensitivities obtained from our previous works. The present AuNPs showed a higher reactivity compared to the ones used in our previous studies indicated here with an improvement of the sensitivity of a GC/ AuNPs sensor between 5 and 10 times, depending on the experimental conditions. This feature shows that our synthesis and use of the AuNPs may be optimized for this sensor. Then for this present work, comparable sensitivities are noticeable between GC/AuNPs and GC/SH/AuNPs whereas the GC/NBD/AuNPs is almost ten times less sensitive than the first two interfaces. This result is not surprising given the lack of interactions between nitro groups and gold that lead to a less amount of AuNPs on the surface. Also, one can suppose that the low interactions between the NBD layer and the AuNPs can be an obstacle to the electron flow toward the carbon surface and lead to a smaller sensitivity.

On the other hand the addition of the SH layer seemed to slightly enhance the sensitivity compared to the diazonium-free electrode. This observation is even clearer with the surface normalized sensitivities because with a smaller active surface area, the GC/SH/AuNPs sensor exhibited a comparable performance than the GC/AuNPs one. This result may prove that the interactions between $\mathrm{S}$ and AuNPs are promoted compared to the ones between $\mathrm{C}$ from GC and AuNPs because of the natures of the bonds involved: covalent for $\mathrm{S}-\mathrm{Au}$ and adsorption for $\mathrm{C}-\mathrm{Au}$. In addition, one can suppose that during the SWASV preconcentration step, mercury is more easily reduced on the AuNPs because of the presence of the $\mathrm{SH}$ layer. Indeed, $\mathrm{Hg}$ is known for showing a great affinity with $\mathrm{S}$ that could promote this reduction, and then increase the sensitivity of the $\mathrm{GC} / \mathrm{SH} / \mathrm{AuNPs}$ interface compared to the diazonium-free one.

The performances of the interfaces as they were prepared in this study were also compared to some obtained with sensors from the literature (see Table 4). Because of the very short preconcentration time used in this current work, the normalized sensitivities for GC/ AuNPs and GC/SH/AuNPs interfaces were greatly enhanced compared to the one from other research group studies, between 4 and 1000 times better depending on the interface considered. Here again, this behavior outlined the great reactivity of the chemicallyprepared AuNPs during this study that allowed to reduce the preconcentration time to a minimum value. On the other hand, the sensitivity of the GC/NBD/AuNPs interface tended to be in the same order of magnitude as the ones from the literature e.g. Abollino et al. [61] and Li et al. [62].

\section{Conclusion}

In this work GC electrodes were functionalized using chemically-prepared AuNPs and two different diazonium salts; for 
Table 4

Normalized sensitivities ( $\mu \mathrm{A} \mathrm{lnmol}{ }^{-1} \mathrm{~min}^{-1}$ ) of different sensors from the literature; the preconcentration times are given in seconds. E: electrodeposit; DC: Drop casting.

\begin{tabular}{|c|c|c|c|c|c|c|}
\hline & Abollino et al. [61] & Ding et al. [63] & Gong et al. [20] & Li et al. [62] & Giannetto et al. [21] & Xu et al. [64] \\
\hline Functionalized electrode & GC/AuNPs & $\mathrm{GC} / \mathrm{rGO} / \mathrm{AuNPs}^{\mathrm{a}}$ & GC/chi-graphene/AuNPs ${ }^{b}$ & CFME/AuNPs ${ }^{c}$ & GC/PEDOT/AuNPs ${ }^{\mathrm{d}}$ & GC/MWCNT/AuNPs \\
\hline AuNPs deposition & $\mathrm{E}$ & $\mathrm{E}$ & $\mathrm{E}$ & In situ & DC & DC \\
\hline Mercury detection method & SWASV & ASV & SWASV & DPASV & DPV & DPASV \\
\hline Preconcentration time & 120 & 600 & 120 & 120 & 100 & 300 \\
\hline Normalized sensitivity & 0.652 & 0.008 & 0.071 & 0.151 & 0.003 & 0.024 \\
\hline
\end{tabular}

a rGO: Reduced Graphene Oxide.

b chi: chitosan.

c CFME: Carbon Fiber Mat Electrode.

d PEDOT: Poly(3,4-ethylenedioxythiophene).

e MWCNT: Multi Walled Carbon Nanotubes.

the sake of comparison a third electrode bearing only AuNPs was also elaborated. The organic layers were electrochemically grafted by constant potential electrolysis and the AuNPs drop-casted on the interfaces. First, the results showed that the AuNPs deposits are heterogeneous due to complex processes taking place during solvent evaporation that also lead to the formation of $\mathrm{NaCl}$ crystals and skin all over the electrode. Then, the functionalization monitoring operated with two electrochemical probes suggested that AuNPs may interpenetrate inside the thiol-diazonium layer while they remain at the surface of the nitro one. However, these organic layers do not seem to have any effect on the dissolution/redeposition behavior of the AuNPs during activation in $\mathrm{H}_{2} \mathrm{SO}_{4}$ that lead to a severe decrease in active surface area. On the other hand the interfaces functionalized with the diazonium layers showed a good stability in terms of particles density over one month of storage under acidic conditions. Concerning mercury detection, the high reactivity of chemically-prepared AuNPs compared to the electrogenerated ones allowed to reduce the preconcentration time during the SWASV process to $30 \mathrm{~s}$ and obtain a normalized sensitivity up to $3.94 \mu \mathrm{Alnmol}{ }^{-1} \mathrm{~min}^{-1}$ in the range $1-10 \mathrm{nmoll}^{-1}$. Future works will now focus on the establishment of a new activation process to maintain the AuNPs active surface area available.

\section{Acknowledgement}

The authors are grateful to François Guérin from the Atelier Interuniversitaire de Micro-nano Electronique (AIME - INSA Toulouse) for his help in FEG-SEM micrographs recording and to Dr Childérick Séverac (Institut des Technologies Avancées en sciences du Vivant (ITAV, Toulouse) for AFM measurements. They also thank Dr Yann Leroux (Institut des Sciences Chimiques de Rennes) for PPF providing and helpful discussion on its handling, Dr Martine Meireles (LGC, Toulouse) for fruitful discussion on drop-casted deposits and Dr Laurent Massot (LGC, Toulouse) for his kind help.

\section{References}

[1] R. Yin, C. Gu, X. Feng, L. Zheng, N. Hu, Transportation and transformation of mercury in a calcine profile in the wanshan mercury mine, SW China, Environ. Pollut. 219 (2016) 976-981.

[2] L.A. Mendes, J.C. de Lena, C.M. do Valle, P.M. Fleming, C.C. Windmöller, Quantification of methylmercury and geochemistry of mercury in sediments from a contaminated area of Descoberto (MG), Brazil, Appl. Geochem. 75 (2016) $32-43$

[3] D.L. Nguyen, J.Y. Kim, S.-G. Shim, Y.S. Ghim, X.-S. Zhang, Shipboard and ground measurements of atmospheric particulate mercury and total mercury in precipitation over the Yellow Sea region, Environ. Pollut. 219 (2016) 262-274.

[4] Q. Wu, S. Wang, M. Yang, H. Su, G. Li, Y. Tang, J. Hao, Mercury flows in large- scale gold production and implications for Hg pollution control, J. Environ. Sci. (2017), https://doi.org/10.1016/j.jes.2017.03.029.

[5] S.C. Nicklisch, L.T. Bonito, S. Sandin, A. Hamdoun, Mercury levels of yellowfin tuna (Thunnus albacares) are associated with capture location, Environ. Pollut. 229 (2017) 87-93.

[6] D.L. Taylor, P.R. Williamson, Mercury contamination in Southern New England coastal fisheries and dietary habits of recreational anglers and their families: implications to human health and issuance of consumption advisories, Mar. Pollut. Bull. 114 (1) (2017) 144-156.

[7] H.A. de Wit, M.J. Kainz, M. Lindholm, Methylmercury bioaccumulation in invertebrates of boreal streams in Norway: effects of aqueous methylmercury and diet retention, Environ. Pollut. 164 (2012) 235-241.

[8] G. Liu, Y. Cai, T. Philippi, P. Kalla, D. Scheidt, J. Richards, L. Scinto, C. Appleby, Distribution of total and methylmercury in different ecosystem compartments in the Everglades: implications for mercury bioaccumulation, Environ. Pollut. 153 (2) (2008) 257-265.

[9] U. Da Broi, C. Moreschi, A. Colatutto, B. Marcon, S. Zago, Medico legal aspects of self-injection of metallic mercury in cases of suicide or self-harming, J. Forensic Legal Med. 50 (2017) 12-19.

[10] S. Bose-O'Reilly, R. Schierl, D. Nowak, U. Siebert, J.F. William, F.T. Owi, Y.I. Ir, A preliminary study on health effects in villagers exposed to mercury in a small-scale artisanal gold mining area in Indonesia, Environ. Res. 149 (2016) 274-281.

[11] F. Edition, Guidelines for drinking-water quality, WHO Chronicle 38 (2011) 104-108.

[12] U. European, Directive 2013/39/EU of the European Parliament and of the Council of 12 august 2013 amending Directives 2000/60/EC and 2008/105/EC as regards priority substances in the field of water policy, Official Journal of the European Union.

[13] G.A. Gill, W.F. Fitzgerald, Mercury sampling of open ocean waters at the picomolar level, Deep Sea Res. Part A. Oceanogr. Res. Papers 32 (3) (1985) 287-297.

[14] C.R. Hammerschmidt, K.L. Bowman, M.D. Tabatchnick, C.H. Lamborg, Storage bottle material and cleaning for determination of total mercury in seawater, Limnol Oceanogr. Meth. 9 (10) (2011) 426-431.

[15] C. Gao, X.-J. Huang, Voltammetric determination of mercury (II), TrAC Trends Anal. Chem. 51 (2013) 1-12.

[16] M. Ghanei-Motlagh, M.A. Taher, A. Heydari, R. Ghanei-Motlagh, V.K. Gupta, A novel voltammetric sensor for sensitive detection of mercury (II) ions using glassy carbon electrode modified with graphene-based ion imprinted polymer, Mater. Sci. Eng. C 63 (2016) 367-375.

[17] M. Lu, R. Xiao, X. Zhang, J. Niu, X. Zhang, Y. Wang, Novel electrochemical sensing platform for quantitative monitoring of $\mathrm{Hg}$ (II) on DNA-assembled graphene oxide with target recycling, Biosens. Bioelectron. 85 (2016) $267-271$.

[18] L. Yao, J. Teng, M. Zhu, L. Zheng, Y. Zhong, G. Liu, F. Xue, W. Chen, MWCNTs based high sensitive lateral flow strip biosensor for rapid determination of aqueous mercury ions, Biosens. Bioelectron. 85 (2016) 331-336.

[19] O. Abollino, A. Giacomino, M. Ginepro, M. Malandrino, I. Zelano, Analytical applications of a nanoparticle-based sensor for the determination of mercury, Electroanalysis 24 (4) (2012) 727-734.

[20] J. Gong, T. Zhou, D. Song, L. Zhang, Monodispersed Au nanoparticles decorated graphene as an enhanced sensing platform for ultrasensitive stripping voltammetric detection of mercury (II), Sensor. Actuator. B Chem. 150 (2) (2010) 491-497.

[21] M. Giannetto, G. Mori, F. Terzi, C. Zanardi, R. Seeber, Composite PEDOT/Au nanoparticles modified electrodes for determination of mercury at trace levels by anodic stripping voltammetry, Electroanalysis 23 (2) (2011) 456-462.

[22] T. Hezard, K. Fajerwerg, D. Evrard, V. Collière, P. Behra, P. Gros, Influence of the gold nanoparticles electrodeposition method on $\mathrm{Hg}$ (II) trace electrochemical detection, Electrochim. Acta 73 (2012) 15-22.

[23] L. Laffont, T. Hezard, P. Gros, L.-E. Heimbürger, J.E. Sonke, P. Behra, D. Evrard, Mercury(II) trace detection by a gold nanoparticle-modified glassy carbon electrode using square-wave anodic stripping voltammetry including a chloride desorption step, Talanta 141 (2015) 26-32.

[24] E. Granado, E. Gervais, G. Gotti, S. Desclaux, M. Meireles, P. Gros, D. Evrard, 
Mercury(II) trace detection using a glassy carbon electrode functionalized by chemically prepared gold nanoparticles. Influence of coating process on surface reactivity and analytical performances, Int. J. Electrochem. Sci. 12 (2017) 6092-6107.

[25] P. Allongue, M. Delamar, B. Desbat, O. Fagebaume, R. Hitmi, J. Pinson, J.M. Savéant, Covalent modification of carbon surfaces by aryl radicals generated from the electrochemical reduction of diazonium salts, J. Am. Chem. Soc, 119 (1997) 201-207.

[26] J.J. Gooding, Advances in interfacial design for electrochemical biosensors and sensors : aryl diazonium salts for modifying carbon and metal electrodes, Electroanalysis 20 (6) (2008) 573-582.

[27] D. Bélanger, J. Pinson, Electrografting: a powerful method for surface modification, Chem. Soc. Rev. 40 (2011) 3995-4048.

[28] G.K. Ramachandran, T.J. Hopson, A.M. Rawlett, L.A. Nagahara, A. Primak, S.M. Lindsay, A bond-fluctuation mechanism for stochastic switching in wired molecules, Science 300 (2003) 1413-1416.

[29] J.A. Harnisch, A.D. Pris, M.D. Porter, Attachment of gold nanoparticles to glassy carbon electrodes via a mercaptobenzene film, J. Am. Chem. Soc. 123 (2001) 5829-5830.

[30] F. Li, Y. Feng, P. Dong, L. Yang, B. Tang, Gold nanoparticles modified electrode via simple electrografting of in situ generated mercaptophenyl diazonium cations for development of DNA electrochemical biosensor, Biosens. Bioelectron. 26 (2011) 1947-1952.

[31] P. Cui, S. Seo, J. Lee, L. Wang, E. Lee, M. Min, H. Lee, Nonvolatile memory device using gold nanoparticles covalently bound to reduced graphene oxide, ACS Nano 5 (9) (2011) 6826-6833.

[32] L. Laurentius, S.R. Stoyanov, S. Gusarov, A. Kovalenko, R. Du, G.P. Lopinski, M.T. McDermott, Diazonium-derivated aryl films on gold nanoparticles: evidence for a carbon-gold covalent bond, ACS Nano 5 (5) (2011) 4219-4227.

[33] H. Gehan, L. Fillaud, N. Felidj, J. Aubard, P. Lang, M.M. Chehimi, C. Mangeney, A general approach combining diazonium salts and click chemistries for gold surface functionalization by nanoparticle assemblies, Langmuir 26 (6) (2009) 3975-3980.

[34] G. Liu, E. Luais, J.J. Gooding, The fabrication of stable gold nanoparticlemodified interfaces for electrochemistry, Langmuir 27 (2011) 4176-4183.

[35] C. Li, S. Monti, X. Li, Z.R. ans Hans gren, V. Carravetta, Theoretical study of para-nitro-aniline on the Au(111) surface, Surf. Sci. 649 (2016) 124-132.

[36] J. Haccouna, C. Vautrin-Ul, A. Chaussé, A. Adenier, Electrochemical grafting of organic coating onto gold surfaces: influence of the electrochemical conditions on the grafting of nitrobenzene diazonium salt, Prog. Org. Coating 63 (2008) 18-24.

[37] M.C.R. González, A.G. Orive, R.C. Salvarezza, A.H. Creus, Electrodeposition of gold nanoparticles on aryl diazonium monolayer functionalized HOPG surfaces, Phys. Chem. Chem. Phys. 18 (2016) 1953-1960.

[38] J.-M. Noël, D. Zigah, J. Simonet, P. Hapiot, Synthesis and immobilization of Ago nanoparticles on diazonium modified electrodes : SECM and cyclic voltammetry studies of the modified interfaces, Langmuir 26 (10) (2010) $7638-7643$.

[39] L. Lee, Y.R. Leroux, P. Hapiot, A.J. Downard, Amine-terminated monolayers on carbon: preparation, characterization, and coupling reactions, Langmuir 31 (18) (2015) 5071-5077.

[40] S. Ranganathan, R. Mccreery, S.M. Majji, M. Madou, Photoresist-derived carbon for microelectromechanical systems and electrochemical applications, J. Electrochem. Soc. 147 (1) (2000) 277-282.

[41] P.A. Brooksby, A.J. Downard, Electrochemical and atomic force microscopy study of carbon surface modification via diazonium reduction in aqueous and acetonitrile solutions, Langmuir 20 (12) (2004) 5038-5045.

[42] J. Turkevich, P.C. Stevenson, J. Hillier, A study of the nucleation and growth processes in the synthesis of colloidal gold, Discuss. Faraday Soc. 11 (1951) $55-75$.

[43] M. Wuithschick, A. Birnbaum, S. Witte, M. Sztucki, U. Vainio, N. Pinna, K. Rademann, F. Emmerling, R. Kraehnert, J. Polte, Turkevich in new robes: key questions answered for the most common gold nanoparticle synthesis, ACS Nano 9 (7) (2015) 7052-7071.

[44] M.-C. Daniel, D. Astruc, Gold nanoparticles : assembly, supramolecular chemistry, quantum-size-related properties, and applications toward biology, catalysis, and nanotechnology, Chem. Rev. 104 (2004) 293-346.

[45] X. Ji, X. Song. J. Li, Y. Bai, W. Yang X. Peng Size control of gold nanocrystals in citrate reduction : the third role of citrate, J. Am. Chem. Soc. 129 (2007) 13939-13948.

[46] J.K. Kariuki, M.T. McDermott, Formation of multilayers on glassy carbon electrodes via the reduction of diazonium salts, Langmuir 17 (2001) 5947-5951.

[47] A. Omrani, A.A. Rostami, N. Yazdizadeh, M. Khoshroo, Experimental and theoretical studies on carbon surface modification by reduction of in situ generated diazonium salt, Chem. Phys. Lett. 539 (2012) 107-111.

[48] S. Baranton, D. Bélanger, Electrochemical derivatization of carbon surface by reduction of in situ generated diazonium cations, J. Phys. Chem. B 109 (51) (2005) 24401-24410

[49] S.S. Yu, A.J. Downard, Dynamic behavior of organic thin films attached to carbon surfaces, e-J. Surf. Sci. Nanotechnol. 3 (2005) 294-298.

[50] M.D. Raicopol, C. Andronescu, R. Atasiei, A. Hanganu, E. Vasile, A.M. Brezoiu, L. Pilan, Organic layers via aryl diazonium electrochemistry: towards modifying platinum electrodes for interference free glucose biosensors, Electrochim. Acta 206 (2016) 226-237.

[51] L. Pauchard, F. Parisse, C. Allain, Influence of salt content on crack patterns formed through colloidal suspension dessication, Phys. Rev. E 59 (3) (1999) $3737-3740$

[52] J.Y. Kim, K. Cho, S. a Ryu, S.Y. Kim, B.M. Weon, Crack formation and prevention in colloidal drops, Sci. Rep. 5 (2015) 13166-13174.

[53] R.G. Pearson, Hard and soft acids and bases, J. Am. Chem. Soc. 85 (22) (1963) 3533-3539.

[54] Y. Wang, E. Laborda, A. Crossley, R.G. Compton, Surface oxidation of gold nanoparticles supported on a glassy carbon electrode in sulphuric acid medium : contrasts with the behaviour of 'macro' gold, Phys. Chem. Chem. Phys. 15 (2013) 3133-3136.

[55] A.C. Cruickshank, A.J. Downard, Electrochemical stability of citrate-capped gold nanoparticles electrostatically assembled on amine-modified glassy carbon, Electrochim. Acta 54 (2009) 5566-5570.

[56] J.T. Steven, V.B. Golovko, B. Johannessen, A.T. Marshall, Electrochemical stability of carbon-supported gold nanoparticles in acidic electrolyte during cyclic voltammetry, Electrochim. Acta 187 (2015) 593-604.

[57] M.-P.N. Bui, J. Brockgreitens, S. Ahmed, A. Abbas, Dual detection of nitrate and mercury in water using disposable electrochemical sensors, Biosens. Bioelectron. 85 (2016) 280-286.

[58] C. Schopf, A. Martin, M. Schmidt, D. Iacopino, Investigation of Au-Hg amalgam formation on substrate-immobilized individual Au nanorods, J. Mater. Chem. C 3 (2015) 8865-8872.

[59] C. Schopf, A. Wahl, A. Martin, A. O'Riordan, D. Iacopino, Direct observation of mercury amalgamation on individual gold nanorods using spectroelectrochemistry, J. Phys. Colloid Chem. C 120 (2016) 19295-19301.

[60] S.F.L. Mertens, M. Gara, A.S. Sologubenko, J. Mayer, S. Szidat, K.W. Krämer, T. Jacob, D.J. Schiffrin, T. Wandlowski, Au@Hg nanoalloy formation through direct amalgamation: structural, spectroscopic, and computational evidence for slow nanoscale diffusion, Adv. Funct. Mater. 21 (2011) 3259-3267.

[61] O. Abollino, A. Giacomino, M. Malandrino, G. Piscionieri, E. Mentasti, Determination of mercury by anodic stripping voltammetry with a gold nanoparticle-modified glassy carbon electrode, Electroanalysis 20 (1) (2008) 75-83.

[62] D. Li, J. Li, X. Jia, E. Wang, Gold nanoparticles decorated carbon fiber mat as a novel sensing platform for sensitive detection of $\mathrm{Hg}$ (II), Electrochem. Commun. 42 (2014) 30-33.

[63] L. Ding, Y. Liu, J. Zhai, A.M. Bond, J. Zhang, Direct electrodeposition of graphene-gold nanocomposite films for ultrasensitive voltammetric determination of mercury (II), Electroanalysis 26 (1) (2014) 121-128.

[64] H. Xu, L. Zeng, S. Xing, G. Shi, Y. Xian, L. Jin, Microwave-radiated synthesis of gold nanoparticles/carbon nanotubes composites and its application to voltammetric detection of trace mercury (II), Electrochem. Commun. 10 (12) (2008) 1839-1843. 